\title{
Sulphasalazine associated pancytopenia may be caused by acute folate deficiency
}

\author{
ELISABETH C M LOGAN, LORNA M WILLIAMSON, AND D R RYRIE
}

From the Department of Haematology, City Hospital, Nottingham

SUMmary Agranulocytosis and aplastic anaemia associated with sulphasalazine are well recognised, but pancytopenia caused by acute megaloblastic arrest of haemopoeiesis while taking sulphasalazine has not previously been described. We report three patients who, after taking sulphasalazine for over two years, suddenly developed severe pancytopenia with gross megaloblastic changes in the marrow. In two patients there was a good response to high dose oral folic acid but the third required folinic acid. The mechanism appears to be acute folate deficiency, and the requirement for folinic acid in one case suggests that the known inhibition of folate metabolism by sulphasalazine also contributes. The syndrome appears to be associated with high dosage and slow acetylator status. The drug has been successfully restarted at reduced dosage with folate supplements in two patients both of whom were slow acetylators. In the third case, whose acetylator status is not known, progression of her disease led to colectomy.

Sulphasalazine has been used in the treatment of inflammatory bowel disease for many years. Although the therapeutic metabolite appears to be 5 'amino salicylic acid which is minimally absorbed from the colon, the sulphapyridine moiety is responsible for the major haematological side effects: these include aplastic anaemia and haemolysis which are well documented and very rarely megaloblastic anaemia caused by folate deficiency. ${ }^{1-3}$ This has been variously attributed to folate depletion secondary to either active inflammatory bowel disease or to chronic haemolysis induced by the drug. In vitro work has also shown a more specific antifolate action of sulphasalazine $e^{4-7}$ and this may be the cause of the reduced red cell folate levels found in patients on long term maintenance with the drug. ${ }^{8}$ Individuals who are slow acetylators may achieve high plasma sulphapyridine concentrations even on normal dosage. We report three patients, two of whom were slow acetylators, who had received sulphasalazine for some years and who presented acutely ill with pancytopenia apparently due to severe folate deficiency.

\section{Case 1}

A 26 year old man, who had been treated with

Address for correspondence: Dr E C M Logan. Department of Haematology. City Hospital. Nottingham.

Received for publication 17 October 1985 sulphasalazine $2 \mathrm{~g}$ daily for three years for ulcerative pancolitis, presented to his general practitioner with anorexia, tiredness, and a slight increase in bowel frequency. His sulphasalazine was increased to $4 \mathrm{~g}$ daily and 10 days later he was admitted to hospital critically ill with generalised purpura, extensive oral ulceration, and fever of $38^{\circ} \mathrm{C}$. He had few symptoms of bowel disease and there was no evidence of exacerbation of his ulcerative colitis while in hospital. The results of investigations at presentation are shown in the Table. The serum vitamin $B_{12}$ and folate were measured by radioisotopic assays. The high vitamin $B_{12}$ level was associated with an

Table Results of investigations at presentation

\begin{tabular}{lccc}
\hline & Case I & Case 2 & Case 3 \\
\hline Hb g/dl & $5 \cdot 7$ & $7 \cdot 5$ & $4 \cdot 7$ \\
MCV fl & 103 & 88 & 102 \\
WBC $\times 10^{9} / 1$ & $0 \cdot 8$ & $2 \cdot 4$ & $3 \cdot 0$ \\
Neutrophils $\times 10^{4} / 1$ & $0 \cdot 3$ & $0 \cdot 8$ & $1 \cdot 8$ \\
Platelets $\times 10^{9} / 1$ & 12 & 80 & 90 \\
Haptogloblins $\mathrm{g} / \mathrm{dl}(0 \cdot 7-3 \cdot 8 \mathrm{~g} / \mathrm{l})$ & $1 \cdot 2$ & $2 \cdot 2$ & $0 \cdot 3$ \\
LDH $(230-460 \mu / 1)$ & 483 & 516 & 3506 \\
Vitamin B $(200-900 \mathrm{ng} / \mathrm{l})$ & 4700 & - & 80 \\
Serum folate $(2 \cdot 6-14 \mu \mathrm{g} / \mathrm{l})$ & $0 \cdot 1$ & - & $1 \cdot 5$ \\
Red cell folate $(130-640 \mu \mathrm{g} / \mathrm{l})$ & 30 & - &.- \\
Prodromal illness & $?$ viral & bowel & chronic \\
& $? ?$ bowel & relapse & haemolysis/ \\
& relapse & & viral illness \\
\hline
\end{tabular}


extremely high unsaturated $\mathrm{B}_{12}$ binding capacity of $27300 \mathrm{ng} / \mathrm{l}$ (normal 600-1175 ng/l) because of a raised transcobalamin II. His blood film showed a few oval macrocytes but bone marrow examination showed severe megaloblastic change. The red cell series, although megaloblastic was reduced in numbers. Numerous giant metamyelocytes with marked cytoplasmic vacuolation were present. No megakaryocytes were seen.

MANAGEMENT AND PROGRESS (Figure)

On admission his sulphasalazine was stopped. His pyrexia was treated with intravenous cefotaxime and metronidazole and he was given oral folic acid $5 \mathrm{mg}$ twice daily, and one injection of $1000 \mu \mathrm{g}$ hydroxycobalamin. He was also transfused two units of packed cells. Four days later he remained unwell with increasing purpura and persistent fever. The blood count showed a haemoglobin of $8.7 \mathrm{~g} / \mathrm{dl}$, white cell count $0.7 \times 10^{9} / 1$ with $0 \cdot 17 \times 10^{9} / 1$ neutrophils and the platelets remained $10 \times 10^{9} / \mathrm{l}$. Although the serum folate was now $17 \mu \mathrm{g} / \mathrm{l}$ and the red cell folate $129 \mu \mathrm{g} / \mathrm{l}$, the reticulocyte count remained $0 \cdot 1 \%$. A repeat bone marrow aspirate showed persistence of the megaloblastic features, but with a decrease in
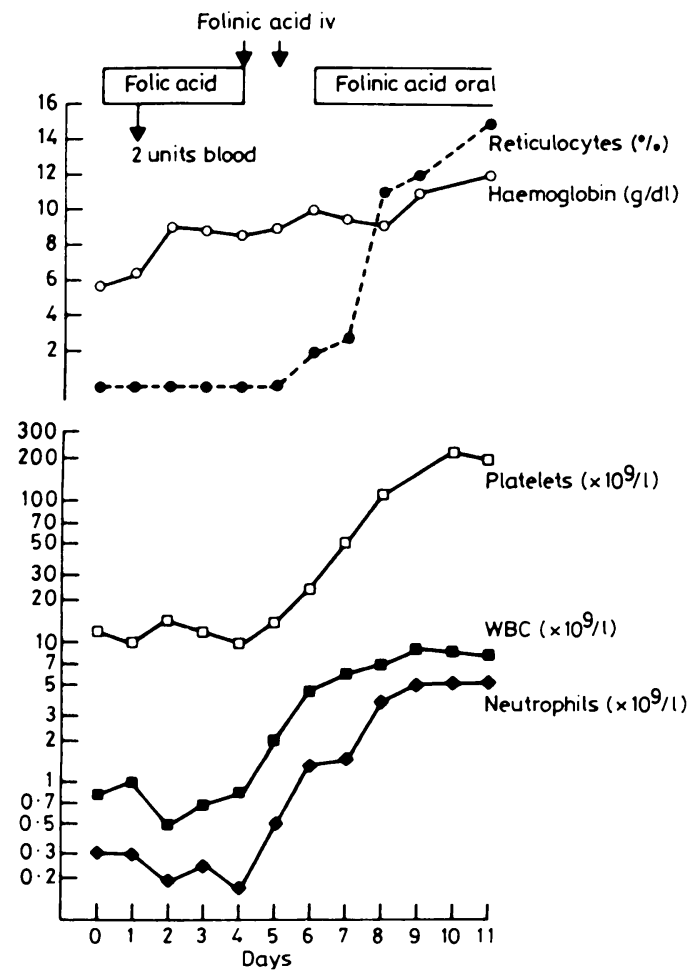

Figure Case 1: haternatological response to treatment. the vacuolation of the myeloid precursors. In view of the lack of response to oral folic acid, intravenous folinic acid was given and in 24 hours the platelet count had risen to $17 \times 10^{9} / \mathrm{l}$ and the white cell count to $2.9 \times 10^{9} / 1$ with $0.5 \times 10^{9} / 1$ neutrophils. Forty eight hours after folinic acid his reticulocytes were $2 \%$ and rose to $15 \%$ five days later, at which time the haemoglobin had also risen to $11.9 \mathrm{~g} / \mathrm{dl}$, platelets to $200 \times 10^{9} / 1$ and white cell count to $8.0 \times 10^{9} / 1$. Since then his blood count has remained normal on $5 \mathrm{mg}$ of folic acid daily, in spite of the reintroduction of sulphasalazine $1.5 \mathrm{~g}$ daily to control his bowel symptoms. Jejunal biopsy carried out two years earlier was normal. His transcobalamin II levels have remained high and are under investigation. He is a slow acetylator.

\section{Case 2}

A 20 year old girl with a three year history of Crohn's disease affecting the bowel from the terminal ileum to the pelvic colon, received sulphasalazine $3 \mathrm{~g}$ daily. She presented extremely ill with excessive tiredness, nausea, and weight loss of $6 \mathrm{~kg}$ in two weeks. For the previous two days she had had three loose stools a day associated with the passage of blood. On admission her temperature was $38^{\circ} \mathrm{C}$ and she had diffuse purpura and pallor. Although relapse of her Crohn's disease was suspected she appeared more ill than her bowel symptoms or signs warranted. Results of initial investigation are given in the Table. Her serum vitamin $\mathrm{B}_{12}$ and folate levels were not measured as the method in use at the time was microbiological and she was receiving antibiotics. Her blood film showed microcytes and macrocytes with hypersegmented neutrophils Bone marrow was megaloblastic but showed prominence of the myeloid series with marked cytoplasmic vacuolation and numerous large cells. Her serum iron and iron binding capacity suggested mild iron deficiency.

MANAGEMENT AND PROGRESS

Sulphasalazine was stopped; she was transfused and given ACTH and intravenous antibiotics. Forty eight hours later she remained extremely ill and review of her case led to the start of folic acid $5 \mathrm{mg}$ three times daily and one injection of $1000 \mu \mathrm{g}$ hydroxycobalamin was given intramuscularly. Forty eight hours later her reticulocyte count was $5 \%$, neutrophils $1.7 \times 10^{9} / 1$ and platelets $110 \times 10^{9} / 1$. She made a steady clinical improvement. A subsequent Schilling test showed normal vitamin $\mathrm{B}_{12}$ absorption. A jejunal biopsy had been normal a year earlier and was not repeated. After this illness, she was labelled 'allergic to sulphasalazine' and recur- 
rence of her bowel symptoms resulted in a colectomy a year later. It has not been possible to determine her acetylator status.

\section{Case 3}

A 16 year old boy, with a two year history of Crohn's disease of the terminal ileum treated with sulphasalazine $3 \mathrm{~g}$ daily, presented with a four week history of lethargy, anorexia, and weight loss. On admission he was ill with a pyrexia of $37.8^{\circ} \mathrm{C}$ and marked pallor, but no evidence of active Crohn's disease, apart from a small anal fissure. Results of investigations are shown in the Table. His blood film was only mildly macrocytic with no morphological evidence of haemolysis. Reticulocytes were $0 \cdot 1 \%$. The neutrophils showed hypersegmentation. Marrow aspirate was hypercellular and grossly megaloblastic with normal megakaryocytes. The myeloid series showed many giant metamyelocytes but no vacuolation. Iron stores were normal.

MANAGEMENT AND PROGRESS

Sulphasalazine was stopped and he was given folic acid $5 \mathrm{mg}$ three times daily and one injection of $1000 \mu \mathrm{g}$ hydroxycobalamin. Forty eight hours later his platelet count was $176 \times 10^{9} / 1$. His haemoglobin remained at $4.8 \mathrm{~g} / \mathrm{dl}$ but his reticulocytes rose to $8 \%$ on day 2 and $57 \%$ on day 5 , when his haemoglobin rose to $5 \cdot 1 \mathrm{~g} / \mathrm{dl}$ and continued to rise to normal levels over the next few weeks. A Schilling test carried out after recovery showed normal absorption of vitamin $B_{12}$. Jejunal biopsy had been normal two years previously and was not repeated. He has since been shown to be a slow acetylator and has restarted sulphasalazine with folate supplements.

\section{Discussion}

The side effects of sulphasalazine may be divided into two major groups. ${ }^{9}$ Firstly there are the more common side effects which are related to plasma levels, and which are therefore dose related and more common in slow acetylators. ${ }^{10}$ These include malaise, vomiting, headaches, methaemoglobinaemia and oxidative red cell damage leading to haemolysis. " Secondly and less commonly, unpredictable hypersensitivity reactions may occur. These develop early in treatment and may cause skin rashes, hepatic and pulmonary dysfunction or aplastic anaemia. The effects of the drug on folate metabolism which we report here appear to be dose related rather than because of hypersensitivity, but like aplastic anaemia can present with acute pancytopenia.

Acute folate deficiency was first described in 1964 by Chanarin and Davey in four pregnant women with urinary tract infections and has since been described in patients receiving intravenous nutrition and in intensive care units. ${ }^{12-15}$ There is arrest in development of all cellular elements of blood and therefore typically presents with pancytopenia. Bone marrow morphology shows abnormalities in all cell lines with reduced or absent megakaryocytes, abnormal granulopoiesis with cytoplasmic vacuolation and giant metamyelocytes, and reduced red cell precursors showing megaloblastic maturation. Acute folate deficiency can develop when an intercurrent illness, which may be mild, temporarily increases folate demands in an individual whose folate stores are already depleted. Patients on long term sulphasalazine may have depleted folate stores with reduced red cell folate levels, but otherwise normal haematological parameters. ${ }^{8}$ There are several reasons for this. Firstly the drug causes oxidative damage to red cells leading to haemolysis and increased folate requirements. ${ }^{3}$ This may present as a gradually progressive anaemia with macrocytosis. Secondly, as shown by Franklin and Rosenberg in 1973, the intact drug sulphasalazine, although neither of its constituents, can impair folate absorption in a competitive manner. ${ }^{4}$ This has since been confirmed ${ }^{56}$ and the observations extended to show specific inhibitory effects of sulphasalazine on the jejunal hydrolysis of pteroylpolyglutamates and thus the absorption of most dietary folates. ${ }^{7}$ In addition, the drug has been shown to competitively inhibit three enzymes involved in the metabolism of folic acid, namely dihydrofolate reductase, serine transhydroxymethylase, and methylene tetrahydrofolate reductase.

Thus, while pancytopenia developing in a patient on sulphasalazine is usually caused by aplastic anaemia or by bone marrow necrosis ${ }^{16}$ it may be caused by acute folate deficiency which can be diagnosed by bone marrow examination and estimation of red cell folate levels. We are aware of one previous death from acute folate deficiency due to sulphasalazine, (personal communication JCP Weber) but the incidence may be more common. As 22 of the 27 deaths attributed to sulphasalazine and reported to the committee on Safety of Medicines between 1964-84, were caused by aplastic anaemia, agranulocytosis or undefined pancytopenia, accurate diagnosis is essential. ${ }^{17}$

Each of our three cases had been on sulphasalazine for some years and therefore were likely to have had low folate stores, particularly case 3 who may also have had chronic haemolysis. All cases had normal diets and Schilling tests, carried out after initial treatment with both folate and vitamin $B_{12}$, showed normal absorption with and without intrin- 
sic factor. In the first and third cases folate levels were low at diagnosis but unfortunately because of the microbiological methods in use at the time no levels for vitamin $B_{12}$ or folate are available for case 2 . There is no evidence to suspect that the megaloblastic anaemia was because of vitamin $\mathrm{B}_{12}$ deficiency as her haemoglobin and MCV were normal six months earlier and the rapidity of onset and severity of her symptoms would be unusual in a pure vitamin $\mathrm{B}_{12}$ deficient state. In spite of being given ACTH to treat her Crohn's disease this was still active when the Schilling test was done and this could not have contributed to vitamin $B_{12}$ malabsorption. Clinically and morphologically she was identical to case 1 and other reported cases of acute folate deficiency. The low serum vitamin $B_{12}$ level in case 3 probably reflects the recognised reduction in vitamin $B_{12}$ levels that can occur secondary to severe folate deficiency ${ }^{18}$ as again there is no reasonable explanation for why he should have become deficient in vitamin $B_{12}$ as a primary cause of his megaloblastic state. All three became acutely megaloblastic during either an intercurrent illness or relapse of their bowel condition. The time between the start of treatment with sulphasalazine and the onset of probable acute folate deficiency is suggestive of a dose dependent effect related to plasma levels of sulphapyridine rather than a hypersensitivity reaction, and indeed two of the three patients are slow acetylators. The response of cases 2 and 3 to high doses of oral folic acid would be expected if the drug were competitively inhibiting folate absorption and metabolism. In case 1 , this form of therapy was inadequate, but the dramatic haematological response to folinic acid, which bypasses the folate metabolising enzymes known to be inhibited by sulphasalazine, suggests that a metabolic block was present. A competitive action of the drug is also suggested by the fact that cases 1 and 3 have safely been restarted on the drug with folate supplements and are now haematologically normal.

The first case had a very high transcobalamin II level but further investigation of this has shown it to be capable of normal transfer of vitamin $B_{12}$ into transformed lymphocytes and reticulocytes. It is unlikely therefore that the very low red cell folate was secondary to reduced cellular vitamin $B_{12}$ which is required for normal entry of folic acid into red cells.

While acute folate deficiency is an uncommon unwanted effect of sulphasalazine it can be a life threatening event in previously well controlled patients and may be precipitated by a mild intercurrent illness or an exacerbation of inflammatory bowel disease resulting in increased folate demands. Acute folate deficiency results when the tissues are already folate depleted through the antifolate actions of maintenance sulphasalazine. This may present as a sudden drop in haemoglobin with a pancytopenia but only minimal macrocytosis in the peripheral blood. Large doses of oral folic acid may be sufficient treatment but intravenous folinic acid may be necessary as a rapid means of overcoming the antifolate actions of sulphasalazine. This effect of sulphasalazine does appear to be a dose related phenomenon and should not be considered a contraindication to later reintroducing sulphasalazine in a reduced dosage.

We should like to thank Professor Michael Langman, Dr Duncan Bell and Dr Anne Ferguson for allowing us to report their patients. We are also grateful to Dr R F A Logan for helpful criticism and Mrs Sue Saunders for typing the manuscript.

\section{References}

1 Schneider R, Beeley L. Megaloblastic anaemia associated with sulphasalazine treatment. Br Med J 1977; 2: 1638-9.

2 Kane SP, Boots MA. Megaloblastic anaemia associated with sulphasalazine treatment. Br Med J 1977; 4: 1287.

3 Swinson CM, Perry J, Lumb M, Levi AJ. Role of Sulphasalazine in the aetiology of folate deficiency in ulcerative colitis. Gut 1982; 22: 456-61.

4 Franklin JL, Rosenberg IH. Impaired folic acid absorption in inflammatory bowel disease: effects of salicylazosulfapyridine (azulfidine). Gastroenterology 1973; 64: $517-25$.

5 Dhar GJ, Selhub J, Rosenberg IH. Asulfidine inhibition of folic acid absorption: confirmation of a specific saturable transport mechanism. [Abstract]. Gastroenterology 1976; 70: A878.

6 Selhub J, Dhar GJ, Rosenberg IH. Inhibition of folate enymes by sulfasalazine. J Clin Invest 1978; 61: 211-4.

7 Halsted CH, Gandhi G, Tamura T. Sulfasalazine inhibits the absorption of folates in ulcerative colitis. $N$ Engl J Med 1981; 305: 1513-7.

8 Longstreth GF, Green R. Folate status in patients receiving maintenance doses of sulphasalazine. Arch Intern Med 1983; 143: 902-4.

9 Taffet SL, Das KM. Sulphasalazine; adverse effect and desensitization. Dig Dis Sci 1983; 28: 833-42.

10 Das KM, Eastwood HA, McManus JPA, Sircus W. Adverse reactions during salicylazosulfapyridine therapy and the relation with drug metabolism and acetylator phenotype. $N$ Engl J Med 1973; 289: 491-5.

11 Pounder RE, Craven ER, Henthorn JS, Melinda Bannatyne. Red cell abnormalities associated with sulphasalazine maintenance therapy for ulcerative colitis. Gut 1975; 16: 181-5.

12 Chanarin I, Davey DA. Acute Megaloblastic Arrest of haemopoiesis in pregnancy. $\mathrm{Br} J$ Haematol 1964; 10: 314-9.

13 Wardrop CAJ, Heatly RW, Tennant GB, Hughes LE. 
Acute folate deficiency in surgical patients on aminoacid/ethanol intravenous nutrition. Lancet 1975; 2: 640-1.

14 Wardrop CAJ, Lewis MH, Tennant GB, Williams RHP, Hughes LE. Acute folate deficiency associated with intravenus nutrition with aminoacid-sorbitolethanol: prophylaxis with intravenous folic acid. $B r J$ Haematol 1977; 37: 521-6.

15 Beard MEJ, Hatipov CS, Hamer JW. Acute marrow folate deficiency during intensive care. Br Med J 1978; 1: $624-5$.
16 Van de Pette JEW, Cunnah DTE, Shellcross TM, Bone marrow necrosis after treatment with sulphasalazine. Br Med J 1984; 289: 798.

17 Committee on Safety of Medicines Adverse Reaction Information Service Salazopyrin 1984.

18 Linnel JC. The fate of cobalamins in vivo. In: Babior B $\mathrm{M}$ ed Cobalamin: biochemistry and pathophysiology. New York: John Wiley, 1975: 287-333.

19 Sheppard K, Ryrie D. Changes in serum levels of cobalamin and cobalamin analogues in folate deficiency. Scand J Haematol 1980; 25: 401-6. 